Шарова Анна Борисовна

Описание Европейской части России и Сибири в географическом сочинении Утида Масао

\title{
"Ёти сиряку"
}

Данная статья посвящена описанию Европейской части России и Сибири в географическом сочинении "Ёти сиряку" ("Краткое описание мира", 1871-1880) японского ученого-западника первой половины XIX века Утида Macao (1839-1876). Географический труд "Ёти сиряку" считается первой обширной энциклопедией по мировой географии, изданной в эпоху Мэйдзи (1868-1912). В связи с установлением дипломатических отношений Российской империи с Японией в 1855 г. Япония, находящаяся в непосредственной близости от границ России, вероятно, питала особый интерес к соседней стране. В статье автор ставит перед собой задачу проанализировать, какой образ Российской империи формируется на страницах географического сочинения "Ёти сиряку".

Адрес статьи: www.gramota.net/materials/9/2020/1/14.html

\section{Источник}

\section{Манускрипт}

Тамбов: Грамота, 2020. Том 13. Выпуск 1. С. 70-74. ISSN 2618-9690.

Адрес журнала: www.gramota.net/editions/9.html

Содержание данного номера журнала: www.gramota.net/materials/9/2020/1/

\section{() Издательство "Грамота"}

Информация о возможности публикации статей в журнале размещена на Интернет сайте издательства: www.gramota.net Вопросы, связанные с публикациями научных материалов, редакция просит направлять на адрес: hist@gramota.net 
в течение 1914-1919 гг., когда повстанцы контролировали большую часть Киренаики и Триполитании [10]. При этом следует понимать, что даже те права, которыми итальянское правительство формально наделило ливийцев в 1919 г., были ограниченными и большей частью оставались на бумаге. Поле того как к власти в Риме пришло фашистское правительство, оно постепенно отвоевало контроль над Ливией и лишило ливийцев значительной части даже тех ограниченных гражданских прав, которыми они были наделены прежде. Вместе с тем фашистское правительство не оставляло попыток заигрывать с коренным населением Ливии и периодически издавало акты, которые расширяли права небольшой, приближенной к итальянцам категории ливийского населения. В то же время к концу 1930-х Италия пошла по пути своего немецкого союзника и стала воплощать принципы расизма в своем государственном строительстве. Поражение во Второй мировой войне не дало Италии глубже развить эти принципы в Ливии.

Список источников

1. Прошин Н. И. История Ливии (конец XIX в. - 1969 г.). М.: Наука, 1975. 415 с.

2. Archivio della Camera dei Deputati. 1937 . Vol. $1354,506-521$ cc. $(16$ cc.)

3. Atti del terzo Congresso di studi coloniali. 12-17 aprile 1937, Firenze, II sezione (Giuridica), Sansoni, Firenze, 1937, vol. III, p. 57-67.

4. Gray J. C., Silverman L. The Fate of Italy's Colonies. L.: Fabian Publications, 1948. 120 p.

5. La legge del 26 giugno 1927 n. 1013 // Gazzetta Ufficiale. 1927. № 148. del 28 guigno.

6. Nuova Antologia. Fascicolo 1599 - 1 novembre 1938.

7. Pro memoria del Maresciallo d'Italia Rodolfo Graziani. Cirene, il 22 ottobre 1940, A.S.M.A.I., Affari Politici, Elenco III/c.91 fasc.292: Cittadinanza italiana speciale ai musulmani libici.

8. Renzo F. de. Jews in an Arab Land: Libya 1835-1970. Austin: University of Texas Press, 1985. 420 p.

9. Rochat G. Il Colonialismo Italiano. Torino: Loescher, 1973. 224 p.

10. Vandewalle D. A History of Modern Libya. Cambridge: Cambridge University Press, 2012. 292 p.

\title{
Civil Status of Aboriginal Population of Italian Libya (1911-1943)
}

\author{
Korobov Semen Aleksandrovich \\ Institute for African Studies of the Russian Academy of Sciences, Moscow \\ simeon.korobov@gmail.com
}

\begin{abstract}
The article examines evolution of the Libyans' civil status in the colonial period. The author examines suppression of the Libyan resistance by the Italian troops and Italy's attempts to involve the Libyans into cooperation with the colonial administration. Influence of the fascist putsch in Rome on the policy of cooperation with the Libyans is identified. It is shown how with rapprochement of Italy and Nazi Germany the ideology of racism (previously non-distinctive for Italy) established itself as an official one, which resulted in further deprivation of the Libyans' rights. Comparative analysis of Italy's policy in other colonies is conducted.
\end{abstract}

Key words and phrases: Libya; Italy; colonialism; imperialism; fascism.

УДК 93/94; 433

https://doi.org/10.30853/manuscript.2020.1.14

Дата поступления рукописи: 24.11.2019

Данная статья посвящена описанию Европейской части России и Сибири в географическом сочинении «Ёти сиряку» («Краткое описание мира», 1871-1880) японского ученого-западника первой половины ХІХ века Утида Масао (1839-1876). Географический труд «Ёти сиряку» считается первой обширной энциклопедией по мировой географии, изданной в эпоху Мэйдзи (1868-1912). В связи с установлением дипломатических отношений Российской империи с Японией в 1855 г. Япония, находящаяся в непосредственной близости от грании России, вероятно, питала особый интерес к соседней стране. В статье автор ставит перед собой задачу проанализировать, какой образ Российской империи формируется на страницах географического сочинения «Ёти сиряку».

Ключевые слова и фразы: Утида Масао; «Ёти сиряку»; эпоха Мэйдзи; Европейская часть России; Сибирь.

\section{Шарова Анна Борисовна}

Российский университет дружбы народов, г. Москва

anchyk90@yandex.ru

\section{Описание Европейской части России и Сибири в географическом сочинении Утида Масао «Ёти сиряку»}

Принято считать, что в эпоху Эдо (1603-1868) Япония была закрытой страной и сохраняла торговые связи лишь с Голландией. И хотя начиная с конца XVIII века Россия неоднократно предпринимала попытки 
установить дипломатические отношения с Японией, однако ни одна из них не принесла желаемого результата: ни экспедиция Павла Лебедева-Ласточкина (1778-1779), ни миссия Адама Лаксана (1792), ни экспедиция Н. П. Резанова (1811-1813) не смогли достичь поставленных целей. И только лишь подписание Симодского трактата (1855) миссией Е. В. Путятина (1803-1883) способствовало установлению дипломатических и торговых отношений между Российской империей и Японией, стало отправной точкой для развития дальнейших взаимоотношений между двумя странами.

В начале периода Мэйдзи (1868-1912) важная роль стала уделяться изучению западных наук, и в том числе мировой географии. Первой обширной энциклопедией стран мира того периода принято считать географическое сочинение Утида Масао (内田正雄 1839-1876) «Ёти сиряку» («Краткое описание мира», 團地誌略). Энциклопедия состоит из тринадцати томов. Она издавалась на протяжении 9 лет (1871-1880) и была призвана познакомить читателей с географией и историей других стран.

Автор энциклопедии - Утида Масао (内田正雄 1839-1876) - был известным во второй половине ХIX века ученым-западником, просветителем, писателем, переводчиком. В юности, как подающий большие надежды выпускник Морского училища г. Нагасаки, он был отправлен в Голландию в составе миссии в связи со строительством фрегата «Кайё: мару» (開陽丸), который, как предполагалось, должен был стать самым большим кораблем во всей Азии [1, p. 169]. Во время пребывания Утида Масао в Европе им был собран целый ряд западных учебников и журналов по мировой географии, послуживших основой создания первой обширной энциклопедии по мировой географии «Ёти Сиряку».

Цель данной статьи - на примере географического сочинения «Ёти Сиряку» японского мыслителя, писателя и переводчика Утида Масао проанализировать описание России в целом, сравнить описания глав, посвященных Европейской части и Сибири, и посмотреть, какой образ страны складывается на страницах энциклопедии.

Актуальность статьи обусловлена тем фактором, что на данный момент между Россией и Японией до сих пор не существует мирного договора, а представления стран друг о друге подчас основаны на устоявшихся образах, стереотипах. В свою очередь, «Ёти сиряку» является первым масштабным сочинением по мировой географии, написанным в середине второй половины XIX в., в котором предлагались достоверные сведения о странах мира, в том числе о России. В этой связи представляется важным рассмотреть, какой изначальный образ России формировался в сознании людей того периода.

Научная новизна данной статьи состоит в том, что исследование основано на источнике, который впервые вводится в научный оборот в российском японоведении.

Описанию России в географическом сочинении отводится довольно большое место. Оно состоит из двух частей: Европейская часть (22 разворота, включая иллюстрации и карты) включена в раздел «Европа», VII том, тогда как Сибирь и Дальний Восток (10 разворотов, включая иллюстрации и карты) - в раздел, посвященный Азии, II том. Помимо России, в седьмом, заключительном, томе в разделе «Европа» находятся такие страны, как Швейцария, Италия, Греция, Турция, Румыния. Во втором томе, кроме Сибири, имеются описания Китая, Юго-Восточной Азии и Южной Азии. Вероятно, со времени установления дипломатических и торговых отношений между двумя странами Япония начала проявлять особый интерес к своему близлежащему соседу, поэтому Россия в целом рассматривается автором с особым вниманием, что может косвенно выражаться в объеме, который занимает глава, посвященная России. В целом Европейской части России и Сибири отведено 32 разворота, что вполне сопоставимо с объемом, отведенным на описание таких передовых европейских стран, как Англия (37 разворотов) и Франция (40 разворотов). При этом стоит отметить, что в главе о Сибири история региона практически не освещается, и в отдельный раздел она не выделена. Поэтому можно предположить, что если бы в главе, посвященной Сибири, история региона освещалась бы в отдельном разделе, то описание России было бы объемнее. Для сравнения: описанию Японии посвящено лишь 12 разворотов, а Голландии - проводнику европейских знаний для Японии в период Эдо - 18.

В период Мэйдзи энциклопедия «Ёти сиряку» использовалась как один из учебников для школьников, а также в качестве пособия для преподавателей [2, с. 133], поэтому в целом описание каждой страны характеризуется во многом схожей структурой. Так, в начале каждого повествования автор обычно предлагает читателю географическую справку, сообщает о границах страны, ее климате, площади, населении, основных реках и т.д. И в данном случае описание России - Европейской части и Сибири - не стало исключением. В самом начале главы, посвященной Европейской части, восхищаясь масштабами страны, Утида Масао даже приводит следующее сравнение: «...даже в период расцвета при императоре Августе территория Римской империи не превышала 1/3 (от территории России)» [5, с. 3]. Как и другие статьи энциклопедии, описание страны предваряет подробная карта региона. В данном случае, так как в этой главе рассказывается только о Европейской части России, Утида Масао предлагает читателю взглянуть на карту не всей России, а лишь Европейской части.

В качестве основных занятий населения автор выделяет добычу руды, леса, пушнины, охоту, выделку кожи, выращивание зерна, хлопка и сахарных корнеплодов [6, с. 4]. В этой связи Утида Масао отмечает наличие серьезных климатических различий и их влияние на сельское хозяйство: «Не стоит отдельно говорить, что в южной части страны выращивают виноград, а также пять злаков. В частности, недалеко от Черного моря почвы... плодородные. А на землях, примыкающих к побережью Северного моря, кроме мха, не увидишь и нескольких растений...» [Там же].

Далее Утида Масао переходит к описанию политического строя страны. Автор сообщает читателям о наличии императора, Священного Синода и т.д. Любопытна позиция Утида Масао по поводу общего 
уровня развития страны. По его мнению, хотя Россия и находится на пути модернизации, однако высокого уровня просвещения она пока не достигла: «Благодаря Петру I эта страна после периода Средневековья начала свое быстрое развитие, она взяла просвещение из Европы, начала в большом количестве применять достижения цивилизации, и несмотря на то, что процесс обогащения и укрепления страны идет полным ходом... но по причине того, что сознание людей не успевает за этим прогрессом, уровня просвещения страна пока не достигла» [Там же, с. 4-5].

Далее Утида Масао переходит к разбору каждого региона в отдельности. Так, он выделяет Московие (или по-другому называет его еще в тексте «Великороссией», グレートロシア), Балтику, Финляндию, Западную Россию, Польшу, Казань, Астрахань, Южную Россию, Кавказ [Там же, с. 6]. Он пишет об основных городах в том или ином регионе и дает короткую справку о каждом из них. Говоря о Москве, Утида Масао отмечает, что путешественники особенно восхищаются Кремлем, находящимися в нем многочисленными церквями, внутреннее убранство которых напоминает императорский дворец, а также колокольней Ивана Великого с огромным колоколом [Там же, с. 8]. Любопытно, что в отличие, например, от Москвы, говоря о Санкт-Петербурге, Утида Масао не упоминает никаких достопримечательностей, сообщает лишь, что этот город, основанный Петром, в настоящее время является столицей государства, что город чистый и имеет широкие улицы, что в Санкт-Петербурге располагаются военно-морские и военные училища и что город активно участвует в морской торговле [Там же, с. 11-12]. Создается впечатление, что автора как знатока военноморского дела скорее интересуют военные и морские объекты, чем исторические памятники СанктПетербурга. По всей видимости, он стремился в первую очередь показать военную мощь столицы государства. С другой стороны, возможно, на момент написания «Ёти сиряку» объекты, которые для нынешнего читателя имеют уже довольно долгую историю и несут важную историческую ценность, для современников автора таковыми не являлись.

В главе, посвященной России, автор рассказывает не только о крупных городах, но и уделяет внимание меньшим по размеру населенным пунктам. Так, например, повествуя о Туле, автор сообщает, что это главный центр по производству оружия в стране, а говоря о Смоленске, Утида Масао отмечает, что в этих местах проходили ожесточенные бои с французской армией [Там же, с. 9]. Автор не обходит стороной и наличие такого региона, как Малороссия, сообщая, что в древности ее нынешняя столица Киев и город Новгород играли роль древних столиц [Там же, с. 11]. Подробнее о Новгороде автор рассказывает чуть раньше, сообщая, что население города составляет 15 тысяч человек и находится он рядом с озером Ильмень. В былые времена в стране это был один из крупных городов. Однако постепенно он пришел в полный упадок и достиг состояния, в котором находится в настоящий момент [Там же, с. 9]. Возможно, автор уделяет внимание описанию Новгорода, потому что город исторически играл роль крупного торгового центра с Европой, а также занимал важное место во внутренней торговле, хотя напрямую он об этом и не пишет.

Стоит отметить, что Утида Масао предлагает довольно обширную географию российских городов, пусть иногда описание того или иного города состоит всего из одного-двух предложений. Так, на страницах главы, посвященной Европейской части России, он знакомит читателя с такими городами, как Казань, Астрахань, Архангельск, Ярославль, Новгород, Кронштадт, Севастополь, Одесса и др.

Как и всегда, после географического описания страны Утида Масао дает краткую историю государства. В случае России повествование начинается с князя Рюрика и завершается смертью Николая I и восшествием на престол Александра II.

Вместе с разделом об истории страны описание России составляет двадцать два разворота. Помимо карты в главе присутствуют семь иллюстраций: храм Василия Блаженного, Медный всадник, изображение конных повозок на оживленной улице в зимнюю пору, вид на Кронштадт, пушка, финский дом и причал в Астрахани. За исключением изображения конных повозок и пушки, на других иллюстрациях если люди и присутствуют, то они обозначены крайне схематично. Другими словами, они явно не главные. Автора скорее интересуют всевозможные строения, порты, исторические памятники. Одновременно с этим, и в случае представленных иллюстраций, и в случае описания, создается впечатление, что Утида Масао делает особый акцент на военном потенциале страны.

Так, например, в главе, посвященной Голландии, автор также отмечает наличие в стране мощного флота: «С давних пор со времен политики объединения земель, военно-морское дело стало процветать, стало лучшим в Европе, и [страна] даже неоднократно наносила поражение Англии, заставляя ее трепетать» [5, с. 47]. Кроме того, подчеркивается его важность именно с точки зрения ведения торговли, в том числе международной. Вместе с тем в разделе, посвященном описанию Японии, Утида Масао вообще не упоминает ни о какой военной составляющей, хотя, например, автор уделяет целый абзац рассказу о японском языке, чего нет ни в главе о Голландии, ни в главе о России.

Согласно тезису японской исследовательницы Масуно Кэйко, на иллюстрациях, посвященных европейским странам, изображены, в первую очередь, не люди или обычаи данного региона (как, например, в случае с Китаем, странами Азии и т.д.), а строения: музеи, памятники, мосты, соборы, просто панорамы городов. Так как Европа представлялась автору наиболее просвещенной и передовой, то и в качестве иллюстраций он выбирал в основном монументальные сооружения [3, с. 58]. В случае Европейской части России основными объектами изображения также являются строения, что позволяет причислить ее к просвещенным европейским странам. 
Информация о Сибири содержится во втором томе географического труда «ёти Сиряку». Следуя общему правилу описания любого региона, автор начинает с географического положения. Здесь же Утида Масао приводит и численность населения. Он сообщает, что «на территории [Сибири] население составляет примерно двадцать восемь миллионов человек. Русские из них не превышают двух третей» [4, с. 32$]$.

Среди основных занятий местного населения Утида Масао выделяет охоту, рыболовство, выделку кожи: «Местное население отстреливает диких животных и делает из них хорошую кожу, которую продают не только внутри страны, но и экспортируют в Европу» [Там же, с. 38]. Кроме того, «многие народы пасут оленей, впрягают их в сани, едят их мясо, из кожи делают одежду... в зимние месяцы до весны живут в землянках... они еще далеки от просвещения...» [Там же, с. 33].

При описании Сибири автор придает особую важность природному богатству региона, наличию большого количества полезных ископаемых: «В стране этот регион не только первый по выделке кожи, но и по количеству природных ископаемых, там добываются золото, серебро, медь, свинец, олово, кроме того, добывают бриллианты, и в последнее время на Алтае было добыто бриллиантов стоимостью примерно на девяносто миллионов долларов» [Там же, с. 37].

Вкратце Утида Масао описывает целый ряд городов Сибири: Якутск, Иркутск, Томск, Тобольск, Охотск, Николаевск. Он всегда начинает с местоположения города, сообщает о численности населения и далее обычно рассказывает об основном занятии его жителей. Так, описывая Тобольск, автор говорит, что город является центром Западной Сибири и что в нем есть много типографий и фабрик; в Томске занимаются выделкой кожи и даже поставляют ее в Европу, а также в целом активно ведется торговля; в Якутске жители главным образом добывают бивни морского льва и экспортируют их в другие страны [Там же, с. 38-39]. Если в городе присутствует какой-то объект, вызывающий интерес автора, о нем обязательно будет упомянуто в описании. Например, в Тобольске есть двадцать пять храмов (возможно, автору это число показалось значительным в сравнении с численностью населения города - 12 тысяч человек), и многие семьи живут в одинаковых деревянных домах, а в Томске располагается военная школа [Там же, с. 38].

В конце раздела автор предлагает читателю описание Камчатки. Он сообщает, что это полуостров, располагающийся на восточной окраине страны и выступающий в море. На всей территории Камчатки возвышаются горы, высота которых достигает 1500 дзё ${ }^{1}$, среди них постоянно встречаются вулканы. Видимо, чтобы читателю стало более понятно, насколько высоки горы в том регионе, Утида Масао сравнивает их с горой Фудзи, отмечая, что на Камчатке горы намного выше. «[Здесь обитают] много разных видов диких зверей, таких как медведи, бурые медведи, лоси, морские котики и другие животные. Население острова не превышает пятидесяти шести тысяч человек, русских из них одна треть. Местное население ведет жизнь первобытных, далеких от цивилизации дикарей, [они] обычно перемещаются, используя собак. Столицей региона называют находящийся на восточном побережье Петропавловск-Камчатский. Это стратегический военный район России на Восточном море, там находятся военные и пушки. Шестнадцать лет назад во время Севастопольской войны англо-французские военные корабли атаковали этот регион» [Там же, с. 39-40]. Складывается впечатление, что, завершая главу, посвященную Сибири, автор снова хочет подчеркнуть военную мощь Российской империи и, возможно, неприступность ее границ.

Обычно Утида Масао отводит истории страны (региона) целый раздел после географического описания. Однако в случае Сибири довольно скудные исторические сведения вписаны в географическое повествование. Так, Утида Масао вкратце сообщает, что сначала этот регион принадлежал Китаю, но вот уже более трехсот лет находится во владении России. Автор делает акцент на роли, которую исторически выполняла Сибирь, будучи частью России: это было «место ссылки преступников, место, где наказывали преступников, там часто применялись жестокости, однако говорят, что в последнее время был принят смягчающий закон, направленный на установление часов, отведенных на работы» [Там же, с. 37]. Любопытным является тот факт, что в случае описания Японии автор также не выделяет историю в отдельный раздел, а встраивает ее в общее географическое повествование.

В разделе, посвященном Сибири, помимо карты приведены семь иллюстраций, на шести из которых изображены народы, населяющие этот край. Так, читателю предлагаются следующие иллюстрации: танцы шаманок, портреты представителей народов Восточной Сибири, изображение якутчан на упряжке ездовых оленей, деревня местных жителей, иллюстрации шаманки с подзаголовком «Обычаи тунгусов» и изображение сибирских казаков. На последней иллюстрации в этом разделе изображен корабль, заходящий в порт Петропавловска-Камчатского. Тем самым автор словно снова указывает читателю на значимость военного аспекта для России в целом. Судя по характеру иллюстраций, он явно стремится познакомить читателя с народами, населяющими данный регион, с их обычаями. В главе нет ни одного изображения какого-то строения или монументального сооружения: церкви, военной школы, типографии и т.д. Вместо этого на иллюстрациях представлены примеры традиционных обычаев, обрядов примитивных народов: шаманские танцы, езда на оленьей упряжке. Тем самым Утида Масао лишний раз подчеркивает, что этот край «еще далек от цивилизации».

Вместе с тем можно отметить, в случае обоих разделов, посвященных России, иллюстрации отнюдь не всегда коррелируются с тем, о чем повествуется в тесте. Складывается впечатление, что они скорее дополняют текст, создают общее настроение, а не служат визуальным подтверждением написанного.

\footnotetext{
11 дзё примерно равен 303 м.
} 
Описанию Европейской части России и Сибири во II и VII томах отводится довольно большое место, что косвенно может свидетельствовать об особом интересе к России со стороны Японии. В обоих случаях повествования во многом построены автором по схожему принципу: он знакомит читателей с географией региона, его климатом, основными занятиями населения, крупными городами. Тем не менее порядок описания все же немного отличается: в случае Европейской части России история вынесена в отдельный раздел, тогда как в главе, посвященной Сибири, история вписана в общее географическое повествование. Хотя в целом Россия представляется Утида Масао интересной страной с точки зрения наличия богатых природных ресурсов, а также страной, несомненно, очень сильной в военном отношении, однако одновременно с этим автор подчеркивает, что на данный момент страна еще не достигла уровня просвещенной Европы и находится лишь на пути модернизации. Благодаря данному исследованию сделан еще один шаг к пониманию образа России, который формировался в общественном сознании Японии начала периода Мэйдзи.

Список источников

1. Araki S. Ruins on the ocean floor (Salvaging the Kaiyo Maru) // Diving for Science: Proceedings of the Joint American Academy of Underwater Sciences and Confederation Mondiale des Activites Subaquatiques Annual Scientific Diving Symposium (31 October - 3 November 1985) / ed. by C. T. Mitchell. La Jolla, California, USA: Diving for Science, 1985. P. 169-176.

2. 亀井拓. 明治期における地理の教育。小学教育を中心に//文化交涉: Journal of the Graduate School of East Asian Cultures. 2015. № 4. ページ 125-146 (Камэи Ю. Обучение географии в период Мэйдзи: обучение географии в младшей школе // Дискуссии о культуре. 2015. № 4. С. 125-146).

3. 増野恵子。見える民族、見えない民族。「輿地誌略」の世界観 //版画と写真十九世紀後半出来事とイメージ創出 意. 神奈川大学二十一世紀CEOプログラム, 横浜市, 2006. ページ 47-59 (Масино Кэйко. Видимые нации, невидимые нации. Мировоззрение «Ёти сиряку» // Гравюра и фотография: вторая половина XIX века: события и создание образа. Йокогама: Университет Канагава; Программа СЕО XXI век, 2006. С. 47-59).

4. 内田正雄。輿地誌略 (Утида Масао. Краткие записи о земле). 文部書 (Монбусё), 1877. Т. 2. 63 с.

5. 内田正雄。輿地誌略 (Утида Масао. Краткие записи о земле). 南校大学 (Нанко Дайгаку), 1871. Т. 5.85 с.

6. 内田正雄。舆地誌略 (Утида Масао. Краткие записи о земле). 文部書 (Монбусё), 1877. Т. 7.80 с.

\title{
Description of European Russia and Siberia in the Geographical Work "Yochi Shiryaku" by Uchida Masao
}

\author{
Sharova Anna Borisovna \\ Peoples' Friendship University of Russia, Moscow \\ anchyk90@yandex.ru
}

The article analyses the description of European Russia and Siberia in the geographical work "Yochi Shiryaku" ("A Survey of the World", 1871-1880) by the Japanese scientist-westerner of the first half of the XIX century Uchida Masao (1839-1876). The geographical work "Yochi Shiryaku" is considered the first spacious encyclopaedia of the world geography published in Meiji period (1868-1912). In 1855, diplomatic relations with the Russian Empire were established, and Japan, located in the immediate vicinity of the Russian border, apparently showed a special interest in the neighbouring country. The author aims to analyse the representation of the Empire's image in the geographical work "Yochi Shiryaku".

Key words and phrases: Uchida Masao; "Yochi Shiryaku”; Meiji period; European Russia; Siberia. 